\title{
Comparative Phenotype and Genome Analysis of Cellvibrio sp. PR1, a Xylanolytic and Agarolytic Bacterium from the Pearl River
}

\author{
Zhangzhang Xie, Weitie Lin, and Jianfei Luo \\ Guangdong Key Laboratory of Fermentation and Enzyme Engineering, College of Bioscience and Bioengineering, \\ South China University of Technology, Guangzhou 510006, China \\ Correspondence should be addressed to Jianfei Luo; ljfff2002@scut.edu.cn
}

Received 28 February 2017; Revised 3 June 2017; Accepted 18 June 2017; Published 17 July 2017

Academic Editor: Nikolai V. Ravin

Copyright (c) 2017 Zhangzhang Xie et al. This is an open access article distributed under the Creative Commons Attribution License, which permits unrestricted use, distribution, and reproduction in any medium, provided the original work is properly cited.

\begin{abstract}
Cellvibrio sp. PR1 is a xylanolytic and agarolytic bacterium isolated from the Pearl River. Strain PR1 is closely related to Cellvibrio fibrivorans and C. ostraviensis (identity $>98 \%$ ). The xylanase and agarase contents of strain PR1 reach up to 15.4 and $25.9 \mathrm{U} / \mathrm{mL}$, respectively. The major cellular fatty acids consisted of C16:0 (36.7\%), C18:0 (8.8\%), C20:0 (6.8\%), $\mathrm{C}_{15: 0}$ iso 2-OH or/and $\mathrm{C}_{16: 1} \omega 7 \mathrm{c}$ (17.4\%), and $\mathrm{C}_{18: 1} \omega 7 \mathrm{c}$ or/and $\mathrm{C}_{18: 1} \omega 6 \mathrm{c}(6.7 \%)$. A total of 251 CAZyme modules (63 CBMs, 20 CEs, $128 \mathrm{GHs}$, $38 \mathrm{GTs}$, and 2 PLs) were identified from 3,730 predicted proteins. Genomic analysis suggested that strain PR1 has a complete xylan-hydrolyzing (5 $\beta$-xylanases, $16 \beta$-xylosidases, $17 \alpha$-arabinofuranosidases, 9 acetyl xylan esterases, $4 \alpha$-glucuronidases, and 2 ferulic acid esterases) and agar-hydrolyzing enzyme system ( $2 \beta$-agarases and $2 \alpha$-neoagarooligosaccharide hydrolases). In addition, the main metabolic pathways of xylose, arabinose, and galactose are established in the genome-wide analysis. This study shows that strain PR1 contains a large number of glycoside hydrolases.
\end{abstract}

\section{Introduction}

Polysaccharides (e.g., cellulose, hemicellulose, starch, chitin, agar, and pectin) are the most abundant source of organic carbon in the biosphere. Sugars released from polysaccharides are usually used for the production of value-added products, such as biofuels $[1,2]$, antioxidants $[3,4]$, and medicines [5]. However, the complex chemical structures and extensive interconnections of these polysaccharides in the plant cell wall prevent physical, chemical, and enzymatic degradations. For example, endo-1,4- $\beta$-glucanases, exo-1,4- $\beta$-glucanases, and $\beta$-glucosidases are essential in the enzymatic degradation of cellulose [6]; meanwhile, xylanase, xylosidase, arabinofuranosidase, acetyl xylan esterase, glucuronidase, and ferulic acid esterase are important in the complete hydrolysis of hemicellulose [7]. Highly active enzymes from natural microorganisms are desirable given the growing demand of affordable and environmentally friendly methods for the use of polysaccharide as feedstock.

The genus Cellvibrio from the Pseudomonadaceae family was first discussed by Blackall et al. in 1986 [8]. Eight other species, namely, Cellvibrio ostraviensis, C. vulgaris, C. mixtus, C. fibrivorans, C. gandavensis, C. japonicus, C. fulvus, and $C$. diazotrophicus, have been identified to date (LPSN, http://www.bacterio.net/-allnamesac.html). Bacteria from the genus Cellvibrio are usually Gram-negative and aerobic, and these bacteria are known cellulose, xylan, starch, and chitin degraders [8-10]. For example, C. japonicus degrades all of the major plant cell wall polysaccharides (including crystalline cellulose, mannan, and xylan) by the activities of approximately 130 possible glycoside hydrolases [9]; C. mixtus J3-8 is a xylanolytic bacterium with no cellulolytic activity and has a large number of genes that are not annotated [10]. A cyanobacterial syntrophic bacterium Cellvibrio sp. PR1 was isolated from a water sample from the Pearl River. Xylanolytic and agarolytic activities are observed in strain PR1. Based on the bacterial-algal interactions between strain PR1 and microalgae, the microalgal growths were enhanced by coculturing with strain PR1 and by using xylan or xylose as feedstock [2]. To better understand polysaccharide hydrolysis activities and possible syntrophic patterns 
with microalgae, we comparatively studied the phenotypes and genome of strain PR1.

\section{Materials and Methods}

2.1. Bacterial Strains and Culture Medium. Strain Cellvibrio sp. PR1 was isolated from a freshwater sample collected from the Pearl River $\left(23^{\circ} 8^{\prime} \mathrm{N}\right.$ and $\left.113^{\circ} 17^{\prime} \mathrm{E}\right)$. The strain was deposited in the China General Microbiological Culture Collection Center (Beijing, China) and the NITE Biological Resource Center (Tokyo, Japan) under the accession numbers CGMCC 1.14955 and NBRC 110968, respectively.

The medium used for strain PR1 cultivation contains the following: $1.5 \mathrm{gL}^{-1} \quad \mathrm{NaNO}_{3}, \quad 0.04 \mathrm{gL}^{-1} \quad \mathrm{~K}_{2} \mathrm{HPO}_{4}$, $0.075 \mathrm{gL}^{-1} \quad \mathrm{MgSO}_{4} \cdot 7 \mathrm{H}_{2} \mathrm{O}, 0.036 \mathrm{gL}^{-1} \quad \mathrm{CaCl}_{2} \cdot 2 \mathrm{H}_{2} \mathrm{O}, 1 \mathrm{mg}$ of glucose, and $1 \mathrm{ml}$ of trace element solution. The trace element solution contains the following: $2.86 \mathrm{~g} \mathrm{~L}^{-1} \mathrm{H}_{3} \mathrm{BO}_{3}$, $1.86 \mathrm{~g} \mathrm{~L}^{-1} \mathrm{MnCl}_{2} \cdot 4 \mathrm{H}_{2} \mathrm{O}, 0.22 \mathrm{~g} \mathrm{~L}^{-1} \mathrm{ZnSO}_{4} \cdot 7 \mathrm{H}_{2} \mathrm{O}, 0.39 \mathrm{~g} \mathrm{~L}^{-1}$ $\mathrm{Na}_{2} \mathrm{MoO}_{4} \cdot 2 \mathrm{H}_{2} \mathrm{O}, \quad 0.08 \mathrm{~g} \mathrm{~L}^{-1} \quad \mathrm{CuSO}_{4} \cdot 5 \mathrm{H}_{2} \mathrm{O}, \quad 0.05 \mathrm{~g} \mathrm{~L}^{-1}$ $\mathrm{Co}\left(\mathrm{NO}_{3}\right)_{2} \cdot 6 \mathrm{H}_{2} \mathrm{O}, 6 \mathrm{~g} \mathrm{~L}^{-1}$ citric acid, $6 \mathrm{~g} \mathrm{~L}^{-1}$ ferric ammonium citrate, and $1 \mathrm{~g} \mathrm{~L}^{-1} \mathrm{EDTANa}_{2}$. $\mathrm{pH}$ was adjusted to 7.2. Xylan (Sigma-Aldrich, USA), cellulose (Avicel PH-101 and CMC, Sigma-Aldrich, USA), starch (Sigma-Aldrich, USA), and agarose (Sigma, USA) were used as the primary carbon source for testing xylanase, cellulase, amylase, and agarase activities, respectively.

2.2. Morphology and Physiological and Biochemical Analyses. The cells of strain PR1 growing in exponential phase were collected and used for the examination of cell morphology by transmission electron microscopy (H-7650, Hitachi, Japan) at $80 \mathrm{kV}$. NaCl tolerance was tested in culture medium with additional salt concentration ranging from $0 \%$ to $5 \%(\mathrm{w} / \mathrm{v})$. Growth was tested at different temperatures $(4,10,15,20$, $25,30,37,45$, and $55^{\circ} \mathrm{C}$ ) and $\mathrm{pH}$ levels (4-10). The $\mathrm{pHs}$ were adjusted by using disodium hydrogen phosphate-citrate buffer solution (for $\mathrm{pH} 4-8$ ) and borax-sodium hydroxide buffer solution (for $\mathrm{pH}$ 9-10). Anaerobic growth was determined at $30^{\circ} \mathrm{C}$ in an anaerobic chamber for 7 days. Gram staining was performed following the standard Gram procedure. Motility was examined on a semisolid culture medium supplemented with $0.5 \%(\mathrm{w} / \mathrm{v})$ of agar. Catalase and oxidase activities were investigated following the procedures by Barrow and Feltham [11]. $\mathrm{H}_{2} \mathrm{~S}$ production was studied by growing the strain in a tube that contains culture medium supplemented with $5 \mathrm{~g} / \mathrm{L}$ sodium thiosulfate and detected by using a filter-paper strip saturated with lead acetate [12]. Starch hydrolysis was determined on an agar plate supplemented with $2 \mathrm{~g} / \mathrm{L}$ soluble starch and detected by flooding the plate with Lugol's iodine solution, and gelatin hydrolysis was performed by growing colonies on agar plates with $5 \mathrm{~g} / \mathrm{L}$ gelatin and detected by filling the plates with Frazier's reagent [13]. The substrate-utilization profile was determined in triplicate in a nonglucose medium that contains $1 \mathrm{~g} / \mathrm{L}$ of each substrate. Nitrate reduction was tested by API $20 \mathrm{NE}$ (bioMérieux) according to the manufacturer's instructions. The enzyme activities were examined by using API ZYM (bioMérieux). The strips were incubated at $28^{\circ} \mathrm{C}$ for $48 \mathrm{~h}$.
2.3. Genomic DNA GC Content and Fatty Acid Analysis. The genomic DNA of strain PR1 was isolated and purified by using a TaKaRa MiniBEST Bacteria Genomic DNA Extraction Kit (TaKaRa, Dalian, China). The genomic DNA GC content was determined by HPLC according to the method of Mesbah et al. [14], with Escherichia coli K-12 as a reference. Cellular fatty acids were extracted according to the MIDI protocol [15] and identified by using the standard MIDI Sherlock Microbial Identification System (version 6.0).

2.4. $16 \mathrm{~S} r R N A$ Gene Sequence Analysis. The complete $16 \mathrm{~S}$ rDNA sequence of strain PR1 was obtained from its genomic sequence by using the DNAMAN program and was deposited in the GenBank under the accession number KT149658. The $16 \mathrm{~S}$ rRNA gene sequence of strain PR1 and related sequences were aligned by using CLUSTAL X [16]. The phylogenetic trees were reconstructed by the MEGA program version 5 [17] using the neighbor-joining algorithms. Bootstrap values were calculated based on 1,000 replicates.

\subsection{Genome Annotation and CAZyme Family Identification.} The genome of strain PR1 was sequenced by using Illumina HiSeq 2000 sequencer; the methods of data processing and assembly were presented in our previous work [18]. The genomic sequence was deposited in the GenBank database under the accession number JZSC00000000. The predicted genes were annotated by comparing protein sequences against public databases, including Kyoto Encyclopedia of Genes and Genomes (KEGG), Cluster of Orthologous Groups of proteins (COG), Gene Ontology (GO), and Swiss-Prot by using BLASTp with an $e$-value $<0.00001$. Two genomes from the closely related species that include Cellvibrio sp. BR (GenBank accession number AICM00000000.1) and C. japonicus Ueda107 (GenBank accession number CP000934) were selected for the comparative analysis of functional genes that involve carbohydrate metabolism. Gene-encoding glycoside hydrolases (GHs), carbohydrate esterases (CEs), glycosyltransferases (GTs), polysaccharide lyases (PLs), carbohydrate-binding modules (CBMs), and auxiliary activities (AAs) were identified by using the Carbohydrate-Active EnZyme (CAZy) database [19] and dbCAN database [20]. In brief, CAZymes were analyzed based on HMMer searches against the dbCAN database and BLASTp searches against the CAZy database using default parameters and an $E$-value cutoff of $1 e-20$; the annotation was confirmed only when the two database searches yielded positive results; the positive CAZymes were assigned to an EC number.

2.6. Enzyme Activity Assays. The activity assays of xylanase and agarase were performed by using the fermentation broth that was cultured in the medium with xylan and agarose as the primary carbon source. The fermentation was performed in a $1000 \mathrm{~mL}$ Erlenmeyer flask containing $300 \mathrm{~mL}$ of culture media and supplied with $1 \mathrm{~g} \mathrm{~L}^{-1}$ of each carbon source. The cultivation was maintained at $30^{\circ} \mathrm{C}$ on a rotary shaker with a speed of $150 \mathrm{rpm}$. Fermented broths were collected after 24 hours' cultivation. The supernatant from culture medium 


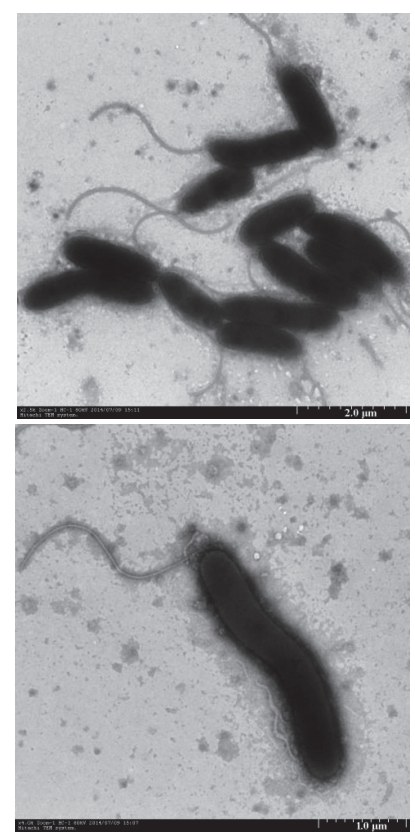

(a)

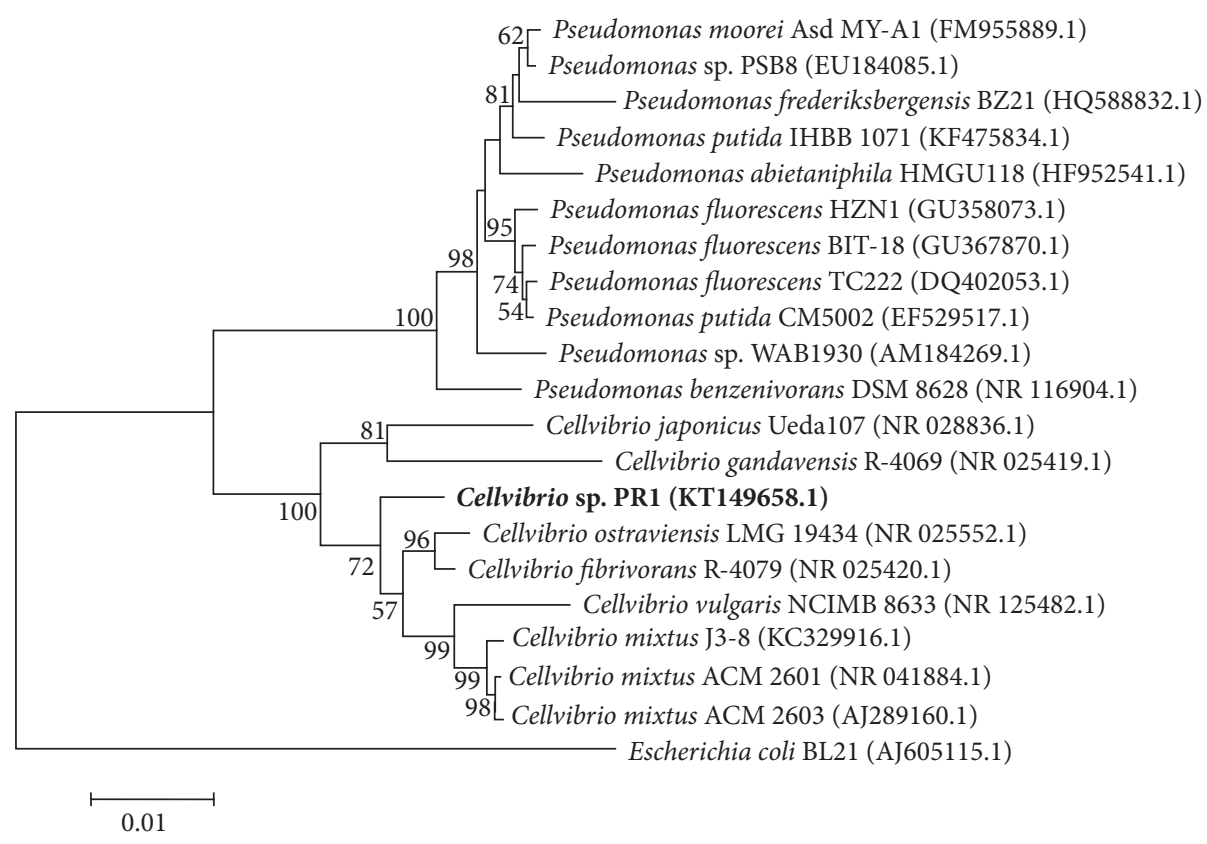

(b)

FIGURE 1: Transmission electron microscope profile (a) and phylogenetic analysis (b) of strain PR1. Neighbor-joining tree was created after computing the evolutionary distances via Kimura's 2-parameter method. Bootstrap values over 50\% based on 1000 replicates are shown.

was collected by centrifugation at $12,000 \times \mathrm{g}$ and $4^{\circ} \mathrm{C}$ for $10 \mathrm{~min} ; 1 \mathrm{ml}$ of supernatant was added to the phosphate buffer solution (PBS, pH 7.0) and modified with $1.0 \%(\mathrm{w} / \mathrm{v})$ of the related substrate for $60 \mathrm{~min}$. The reducing sugar was measured by using the 3,5-dinitrosalicylic acid (DNS) method [21]. One unit of enzyme activity is defined as the amount of enzyme that is released from $1 \mu \mathrm{mol}$ of reducing sugar (as xylose or glucose equivalent) per min. The protein concentrations were determined by the Lowry method and BSA as the standard. The optimal temperatures of the enzyme activities were studied by subjecting reactions to different temperatures ranging from $30^{\circ} \mathrm{C}$ to $50^{\circ} \mathrm{C}$ in a $\mathrm{PBS}(\mathrm{pH} \mathrm{7.0)}$. The $\mathrm{NaCl}$ tolerance of related enzyme was tested under extra $\mathrm{NaCl}$ concentrations ranging from 0 to $5 \%(\mathrm{w} / \mathrm{v})$, and the influence of $\mathrm{pH}$ on enzyme activity was tested under different pHs (4-11); the pHs ( $\mathrm{pH} 3-8$ ) were adjusted by disodium hydrogen phosphate-citrate buffer solution, the $\mathrm{pHs}(\mathrm{pH} 9-$ 10) were adjusted by borax-sodium hydroxide buffer solution, and the $\mathrm{pH} 11$ was adjusted by sodium phosphate-disodium hydrogen phosphate buffer solution.

\section{Results}

3.1. Morphology and Phylogenetic Analysis. Strain PR1 was Gram-negative and nonspore-forming. Cells are straight rod or spiral in shape and are about $1.5-2.5 \mu \mathrm{m}$ long and $0.5 \mu \mathrm{m}$ wide. The cells have single polar flagella with a length of approximately 2-3 $\mu \mathrm{m}$ (Figure 1(a)). Phylogenetic analysis suggested that strain PR1 is under the genus Cellvibrio, and this strain is closely related to C. fibrivorans R-4079 and C. ostraviensis LMG 19434 (Figure 1(b)). The 16S rRNA gene sequence similarities of strain PR1 with C. fibrivorans R-4079 and C. ostraviensis LMG 19434 are more than 98\% and less than $96 \%$ with C. vulgaris NCIMB 8633 (Table 1).

3.2. Comparative Physiological and Biochemical Analysis. Strain PR1 was able to grow at temperatures of $15-45^{\circ} \mathrm{C}$ (optimum at $30-37^{\circ} \mathrm{C}$ ), additional salt of $0-2.5 \% \mathrm{NaCl}$ (optimum at $0-1 \%$ ), and $\mathrm{pH}$ of 6-10 (optimum at $\mathrm{pH} 7-8$ ). The strain is unable to grow under an anaerobic condition. Results show that the strain has a motility capability. It was found that strain PR1 was positive for catalase, oxidase, and starch hydrolysis activities and negative for $\mathrm{H}_{2} \mathrm{~S}$ production and gelatin hydrolysis activities. The main physiological and biochemical characteristics of strain PR1 and related species are shown in Table 1. Strain PR1 utilizes maltose and arabinose (the same as the other five Cellvibrio species), N-acetyl Dglucosamine (except for the C. ostraviensis LMG 19434), and chitin (the same as the C. fulvus LMG 2847 and C. vulgaris NCIMB 8633) for growth. Different from the other five Cellvibrio species, strain PR1 utilizes agar and carboxymethyl cellulose for the growth and shows $\beta$-galactosidase and $\alpha$ fucosidase activities, but leucine arylamidase activity was not observed. Moreover, acid phosphatase, $\beta$-glucosidase, $\alpha$ galactosidase, and $\beta$-Glucuronidase activities were observed in strain PR1, but valine arylamidase and naphthol-AS-BIphosphohydrolase activities were not detected.

The fatty acid compositions of strain PR1 and related strains are summarized in Table 1 . The main fatty acids in strain PR1 were C16:0, C18:0, C20:0, $\mathrm{C}_{15: 0}$ iso 2-OH or/and $\mathrm{C}_{16: 1} \omega 7 \mathrm{c}$ (summed in feature 3 ), and $\mathrm{C}_{18: 1} \omega 7 \mathrm{c}$ or/and $\mathrm{C}_{18: 1} \omega 6 \mathrm{c}$ (summarized in feature 8). Different from the other five species, saturated C16:0 was the most abundant fatty acid in strain PR1 that accounted for $36.74 \%$ of the total fatty acids. 
TABLE 1: Phenotype and fatty acid characteristics of Cellvibrio species.

\begin{tabular}{|c|c|c|c|c|c|c|}
\hline & 1 & 2 & 3 & 4 & 5 & 6 \\
\hline $16 \mathrm{~S}$ rDNA similarity to PR1 (\%) & 100 & 98.6 & 98 & 97.4 & 97.3 & 95.7 \\
\hline $\mathrm{G}+\mathrm{C}$ content $(\mathrm{mol} \%)$ & 49.98 & 48 & $47.4-48.4$ & 52.6 & 44.6 & 44.9 \\
\hline Nitrate reduced to nitrite & + & + & + & - & + & + \\
\hline \multicolumn{7}{|l|}{ Utilization of } \\
\hline Maltose & + & + & + & + & + & + \\
\hline Arabinose & + & + & + & + & + & + \\
\hline Mannose & - & + & + & + & - & - \\
\hline N-Acetyl-D-glucosamine & + & + & - & + & + & + \\
\hline Carboxymethyl cellulose & - & + & + & + & + & + \\
\hline Agar & + & - & - & - & - & - \\
\hline Chitin & + & - & - & - & + & + \\
\hline Valine arylamidase & - & - & + & - & - & - \\
\hline Acid phosphatase & + & + & + & - & - & - \\
\hline$\beta$-Galactosidase & + & - & - & - & - & - \\
\hline$\beta$-Glucosidase & + & + & + & + & + & - \\
\hline$\alpha$-Galactosidase & + & + & + & - & + & + \\
\hline$\beta$-Glucuronidase & + & - & - & - & + & + \\
\hline$\alpha$-Fucosidase & + & - & - & - & - & - \\
\hline Leucine arylamidase & - & + & + & + & + & + \\
\hline Naphthol-AS-BI-phosphohydrolase & - & - & + & + & + & + \\
\hline Growth at $4^{\circ} \mathrm{C}$ (14 days) & - & + & + & - & + & - \\
\hline Growth at $37^{\circ} \mathrm{C}$ & + & - & - & - & - & + \\
\hline Mucoid growth on TSA & - & - & - & + & - & + \\
\hline Yellow pigment on TSA & + & - & + & - & - & + \\
\hline \multicolumn{7}{|l|}{ Fatty acid: } \\
\hline $10: 0$ & 2.33 & $4.8-7.1$ & $4.1-8.2$ & $2.6-5.8$ & 4.20 & $4.3-6.9$ \\
\hline 10:0 3-OH & 2.57 & $7.7-10.7$ & $5.5-13.4$ & 13.00 & 6.50 & $6.1-10.9$ \\
\hline $12: 0$ & 1.99 & $5.4-7.7$ & $4.0-7.2$ & $\operatorname{tr}$ & 4.40 & $4.4-5.8$ \\
\hline $11: 03-\mathrm{OH}$ & - & $0.0-1.1$ & $\operatorname{tr}$ & $\operatorname{tr}$ & - & - \\
\hline $12: 02-\mathrm{OH}$ & - & $3.3-5.4$ & $2.8-6.0$ & $7.8-11.0$ & 3.60 & $2.6-3.9$ \\
\hline $12: 13-\mathrm{OH}$ & 4.06 & - & - & - & 1.30 & - \\
\hline $12: 03-\mathrm{OH}$ & - & $1.0-1.5$ & $\operatorname{tr}$ & $\operatorname{tr}$ & - & - \\
\hline $14: 0$ & 1.97 & $1.6-2.5$ & $1.2-2.4$ & $1.3-1.7$ & $\operatorname{tr}$ & $0.9-1.2$ \\
\hline $15: 0$ & - & $0.0-1.3$ & $\operatorname{tr}$ & $0.9-1.9$ & 2.20 & $\operatorname{tr}$ \\
\hline $16: 0$ & 36.74 & $15.7-20.0$ & $18.5-27.8$ & $14.3-18.0$ & 19.70 & $17.6-20.9$ \\
\hline $17: 0$ & 2.40 & $1.6-4.5$ & $0.0-1.9$ & $2.2-3.7$ & 5.70 & $1.3-2.0$ \\
\hline $17: 1 \omega 8 \mathrm{c}$ & - & $\operatorname{tr}$ & - & $\operatorname{tr}$ & $\operatorname{tr}$ & $\operatorname{tr}$ \\
\hline 18:0 & 8.78 & $0.0-2.8$ & $0.0-1.6$ & $\operatorname{tr}$ & 3.10 & $\operatorname{tr}$ \\
\hline $18: 1 \omega 6 c$ & - & - & $0.0-2.8$ & $0.0-3.3$ & - & $0.0-4.3$ \\
\hline $18: 1 \omega 7 \mathrm{c}$ & - & $11.4-19.0$ & $7.3-15.3$ & $11.3-17.9$ & 16.80 & $12.9-19.8$ \\
\hline $18: 1 \omega 9 c$ & 2.87 & - & - & - & - & - \\
\hline 19:0 & 2.90 & - & - & - & - & - \\
\hline $20: 0$ & 6.81 & - & - & - & - & - \\
\hline ECL 11.799 & - & - & - & - & - & $\operatorname{tr}$ \\
\hline ECL 18.814 & - & $\operatorname{tr}$ & - & - & - & - \\
\hline Summed feature 2 & 2.47 & - & - & - & - & - \\
\hline Summed feature 3 & 17.37 & $25.6-34.0$ & $34.4-38.1$ & $30.4-34.9$ & 30.90 & $34.1-38.2$ \\
\hline Summed feature 8 & 6.75 & - & - & - & - & - \\
\hline
\end{tabular}



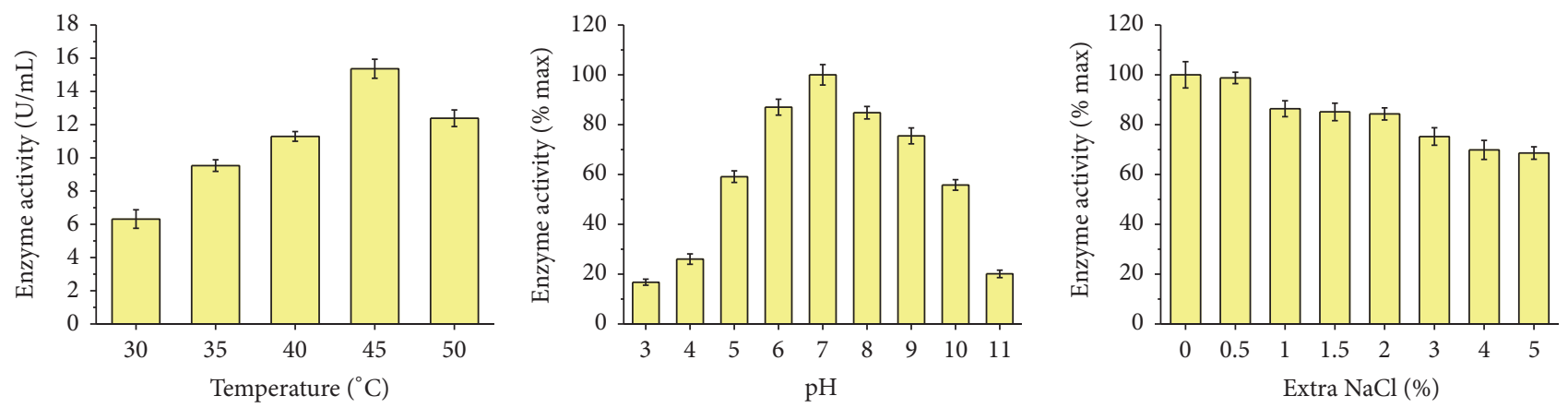

(a)
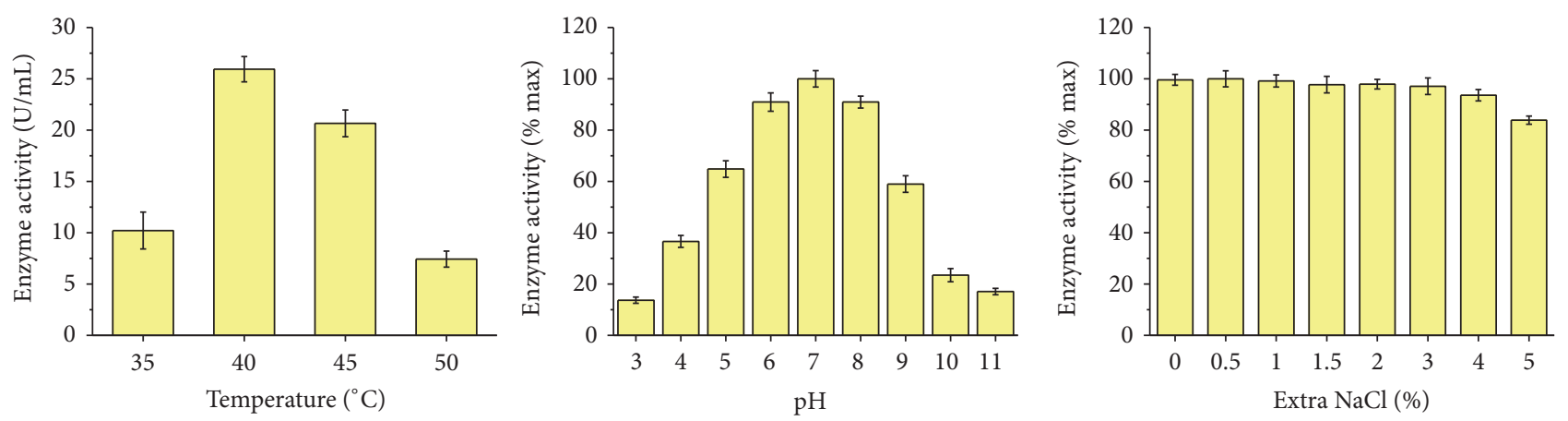

(b)

FIGURE 2: Enzyme activities of xylanase (a) and agarase (b) of strain PR1 at different temperatures, pHs, and $\mathrm{NaCl}$ concentrations.

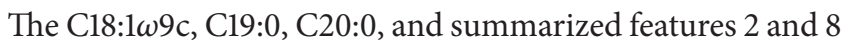
that were not detected in the other five strains were found in strain PR1. These fatty acids accounted for $21.8 \%$ of the total fatty acids. Additionally, the $\mathrm{C} 12: 02-\mathrm{OH}$ and unsaturated C18:1 $\omega 7 \mathrm{c}$ that are abundant in other Cellvibrio species were not identified in strain PR1.

3.3. Enzyme Activities. The extracellular xylanase and agarase activities of strain PR1 were assessed after $48 \mathrm{~h}$ incubation at $30^{\circ} \mathrm{C}$ (Figure 2 ). The optimal xylanase activity from strain $\mathrm{PR} 1$ was determined to be $15.4 \mathrm{U} / \mathrm{mL}$ under the condition of $45^{\circ} \mathrm{C}, \mathrm{pH} 7$, and no extra $\mathrm{NaCl} ; 80.6 \%$ of xylanase activity was observed to remain at $50^{\circ} \mathrm{C}$. When compared to the maximum at $\mathrm{pH} 7$, the xylanase activities continued to have $80 \%$ under $\mathrm{pH} 6-8,16.77 \%$ under $\mathrm{pH} 3$, and $20.11 \%$ under $\mathrm{pH}$ 11. $\mathrm{NaCl}$ was determined to have influence on the xylanase activity; however, the xylanase from strain PR1 was $\mathrm{NaCl}$ tolerant, and it was detected that $68.61 \%$ of enzyme activity was retained under $5 \%(\mathrm{w} / \mathrm{v}$ ) of extra $\mathrm{NaCl}$ (Figure 2(a)).

The optimal agarase activity was determined to be 26.0 U/mL under the condition of $40^{\circ} \mathrm{C}, \mathrm{pH} 7$, and $0.5 \%$ extra $\mathrm{NaCl}$ (Figure 2(b)). It was detected that more than $90 \%$ of agarase activities remained under $\mathrm{pH} 6-8,13.69 \%$ under $\mathrm{pH}$ 3, and $17.07 \%$ under $\mathrm{pH} 11$. Agarase from strain PR1 showed a high tolerance to $\mathrm{NaCl}$, retaining more than $80 \%$ of activity under $5 \%$ of $\mathrm{NaCl}$.

3.4. Comparative CAZyme Family and Functional Genes That Are Involved in Carbohydrate Hydrolysis. The genomic features and CAZyme families of strain PR1, C. japonicus Ueda107, Cellvibrio sp. BR Cellvibrio sp. OA-2007, Cellvibrio sp. PSBB023, C. mixtus, and Cellulomonas gilvus were summarized in Table 2. A total of 3,730 protein-coding genes out of 3,844 ORFs were identified and annotated by BLASTp search with the sequences in databases. CAZyme modules, including 63 CBMs, 20 CEs, 128 GHs, 38 GTs, and 2 PLs, were identified from strain PRl's genome, which was described in our previous report [2]. The distribution of CAZyme family in strain PR1 is similar to the genomes of related strains. CBM6 involved in cellulose/xylan/glucan hydrolysis, CE2 and CE4 involved in xylan hydrolysis, GH13 involved in starch hydrolysis, GH16 involved in agar hydrolysis, GH43 involved in xylan hydrolysis, and GT2 and GT4 involved in UDP-glucose metabolism are dominant in each CAZyme family (Tables S1 and S2, in Supplementary Material available online at https://doi.org/10.1155/2017/6304248).

Strain PR1 has an incomplete cellulose hydrolysis system, which has $4 \beta$-glucosidases and 12 endoglucanase-encoding genes, but a lack of cellobiohydrolase-encoding gene in the genome was observed (Figure 3(a)). The same situation was found in the strain Cellvibrio mixtus that possesses 9 endoglucanases and $12 \beta$-glucosidases but no cellobiohydrolase. Because of the lack, strain PR1 and Cellvibrio mixtus could not grow on cellulose. In contrast, the Cellvibrio japonicus Ueda107, Cellvibrio sp. BR, Cellvibrio sp. OA-2007, and Cellvibrio sp. PSBB023 genomes encode a single cellobiohydrolase that is located in GH6 (the release of disaccharide cellobiose from the reducing ends of the $\beta$-glucan). 
TABLE 2: Genomic feature and CAZyme family of strain PR1 and six related strains.

\begin{tabular}{|c|c|c|c|c|c|c|}
\hline & PR1 & Cellvibrio japonicus & Cellvibrio sp. BR & Cellvibrio sp. OA-2007 & Cellvibrio sp. PSBB023 & Cellvibrio mixtus \\
\hline Genome size $(\mathrm{Mb})$ & 4.43 & 4.58 & 4.85 & 4.59 & 4.7 & 5.18 \\
\hline GC (mol\%) & 47.56 & 52 & 48.8 & 47.7 & 49.4 & 46.66 \\
\hline Total genes & 3,844 & 3679 & 4144 & 4094 & 4062 & 4916 \\
\hline Predict proteins & 3,730 & 3577 & 4047 & 3872 & 3910 & 2845 \\
\hline Annotation percentage (\%) & 97.0 & 97.23 & 97.66 & 94.58 & 96.26 & 57.87 \\
\hline \multicolumn{7}{|c|}{ CAZyme family ${ }^{\mathrm{a}}$} \\
\hline CBMs & 63 & 95 & 105 & 118 & 49 & 121 \\
\hline CEs & 20 & 24 & 33 & 24 & 21 & 27 \\
\hline GHs & 128 & 132 & 159 & 132 & 97 & 135 \\
\hline GTs & 38 & 49 & 54 & 49 & 54 & 58 \\
\hline PLs & 2 & 14 & 0 & 5 & 0 & 0 \\
\hline AAs & 0 & 0 & 3 & 6 & 3 & 9 \\
\hline Total & 251 & 314 & 354 & 334 & 224 & 350 \\
\hline
\end{tabular}

${ }^{a}$ CBMs: carbohydrate-binding modules; CEs: carbohydrate esterases; GHs: glycoside hydrolases; GTs: glycosyl transferases; PLs: polysaccharide lyases; AAs: auxiliary activities.

Xylanase, xylosidase, arabinofuranosidase, acetyl xylan esterase, glucuronidase, and ferulic acid esterase are essential to complete xylan hydrolysis. The xylanase attacks the backbone of xylan and generates oligosaccharides; the xylosidase releases xylose from the oligosaccharides along with the activities of the other four enzymes by attacking the side chains (Figure 3(b)). There are at least 2 GH10 and 2 GH11 and 1 GH $30 \beta$-xylanases, 16 GH43 $\beta$-xylosidases, $17 \alpha$-arabinofuranosidases, 9 acetyl xylan esterases, $2 \alpha$ glucuronidases, and 2 ferulic acid esterases in strain PR1.

The complete hydrolysis of agar/agarose includes two kinds of pathways. (1) $\alpha$-Agarase attacks $\alpha$-1,3-glucosidic bonds to generate agarooligosaccharides, which are hydrolyzed to galactose by the $\beta-1,4-3,6$-anhydro-L-galacopyranose hydrolase. (2) $\beta$-Agarase attacks $\alpha$-1,4-glucosidic bonds to generate neoagarooligosaccharides, which are hydrolyzed to galactose by the $\alpha-1,3$-L-neoagarooligosaccharide hydrolase. The strain PR1 contains 3 GH50 and 1 GH86 $\beta$ agarases along with 2 GH117 $\alpha$-neoagarooligosaccharide hydrolases, whereas only the Cellvibrio sp. BR contains 2 GH50 and 1 GH86 $\beta$-agarases along with 1 GH117 $\alpha$ neoagarooligosaccharide hydrolase (Figure 3(c)).

3.5. The Proposed Metabolic Pathways of Xylan and Agarose on Genome-Wide Analysis. Xylan and agarose are hydrolyzed to xylose, arabinose, galactose, and so forth, in vitro by extracellular enzymes. These monosaccharides are assimilated by cells and take part in energy generation and substance transformation. The main metabolic pathways of xylose, arabinose, and galactose in strain PR1 are proposed on a genomewide analysis. As shown in Figure 4, xylose is converted into xylulose-5-phoshate by the activities of xylose isomerase (XI) and xylulokinase (XK), whereas arabinose is converted into ribulose-5-phosphate by the arabinose isomerase (AI) and ribulokinase (AK). Xylulose-5-phoshpate and ribulose5 -phosphate are interconversed by the ribulose-phosphate 3 -epimerase (RPE) and involved in the pentose phosphate pathway (PPP). The products of PPP, glyceraldehydes-3phosphate, and fructose-6-phosphate are catalyzed to pyruvate via the glycolysis pathway. The genome of strain PR1 has $5 \mathrm{XI}$-encoding, $1 \mathrm{XK}$-encoding, $1 \mathrm{AI}$ - encoding, $1 \mathrm{RK}-$ encoding, and 1 RPE-encoding genes (Figure 4). Galactose is the hydrolysate of agar/agarose and is utilized by strain PR1 via the enzyme catalytic activities of galactokinase (GalK), UDP-glucose 4-epimerase (GalE), UDP-glucosehexose-1-phosphate uridylyltransferase (GalT), UTP-glucose-1-phosphate uridylyltransferase (GalU), and phosphoglucomutase (PGM). The genome of strain PR1 also has 2 GalK-encoding, 2 GalE-encoding, 2 GalT-encoding, 1 GalUencoding, and 2 PGM-encoding genes (Figure 4).

\section{Discussion}

In this work, we comparatively studied the phenotypes and extracellular enzyme activities of strain PR1 and the genomic features and carbohydrate hydrolysis pathways of $C$. japonicus, Cellvibrio sp. BR, Cellvibrio sp. OA-2007, Cellvibrio sp. PSBB023, C. mixtus, and Cellulomonas gilvus were also analyzed. C. fibrivorans R-4079 and C. ostraviensis LMG 19434 were the closely related strains of strain PR1, and the comparative phenotypes and genomes on these strains were also studied; however, only the genome information of $C$. japonicus Ueda107, Cellvibrio sp. BR, Cellvibrio sp. OA-2007, Cellvibrio sp. PSBB023, and C. mixtus J3-8 is available in public databases. This work is still helpful for the investigation of strain PR1 characteristics in a natural ecosystem.

Bacteria from the genus Cellvibrio are known to degrade cellulose, xylan, starch, chitin, and so forth; the members of Cellvibrio species, including C. ostraviensis, C. fibrivorans, C. fulvus, C. vulgaris, C. mixtus, C. gandavensis, C. japonicus, and C. diazotrophicus, were isolated from soils, rhizospheres, and giant snails $[10,22,23]$. Strain PR1 of Cellvibrio was first isolated from freshwater and has xylanolytic and agarolytic activities. $\beta$-Agarases were also observed in Cellvibrio strains 


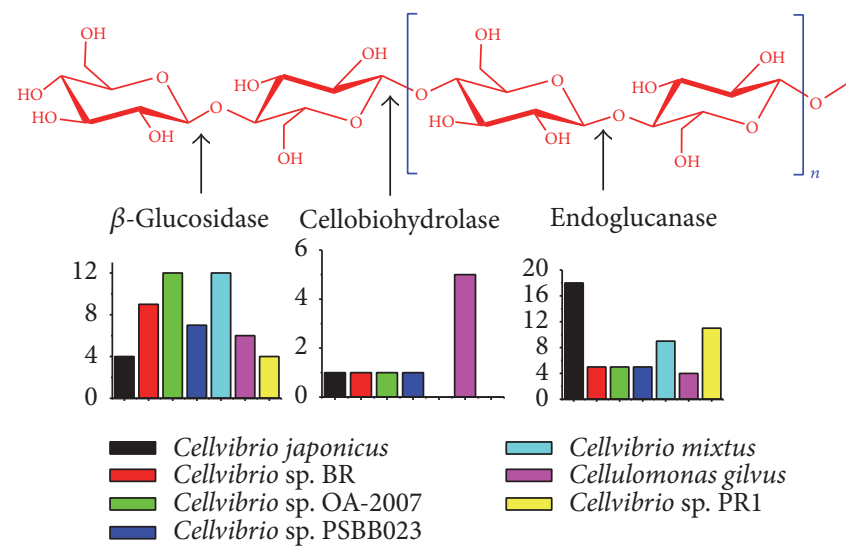

(a) Cellulose hydrolysis

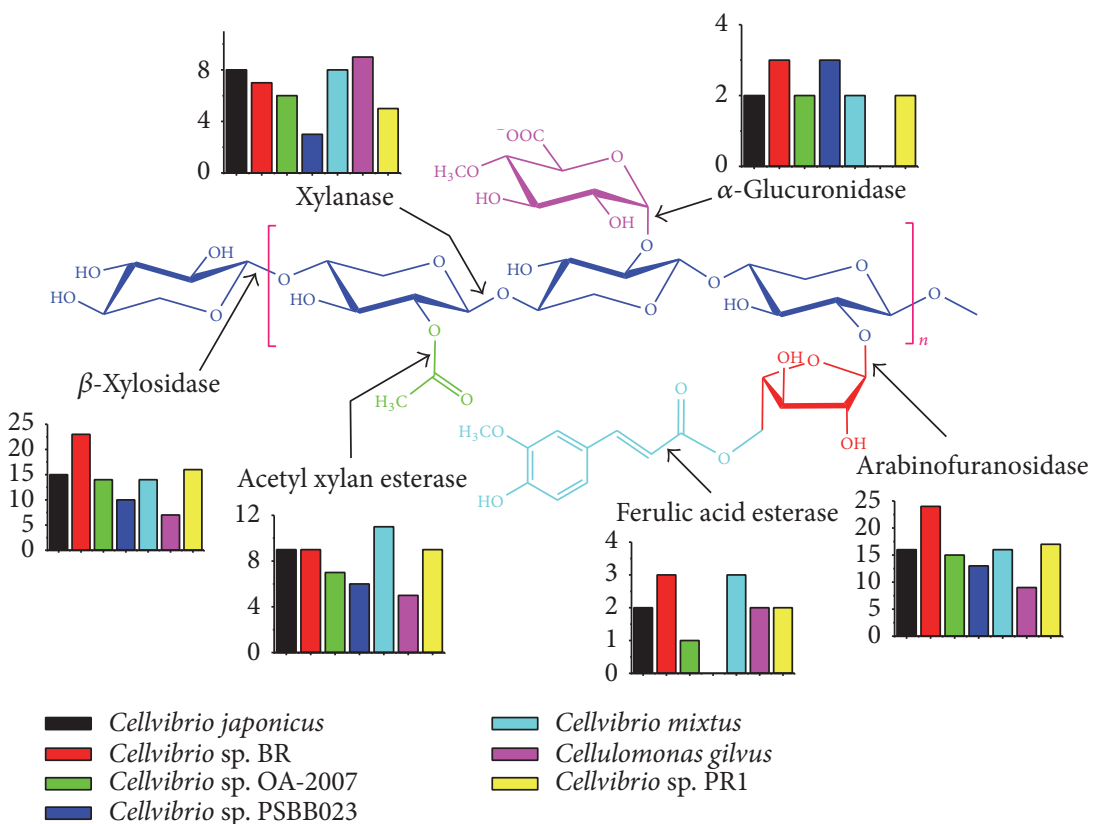

(b) Xylan hydrolysis

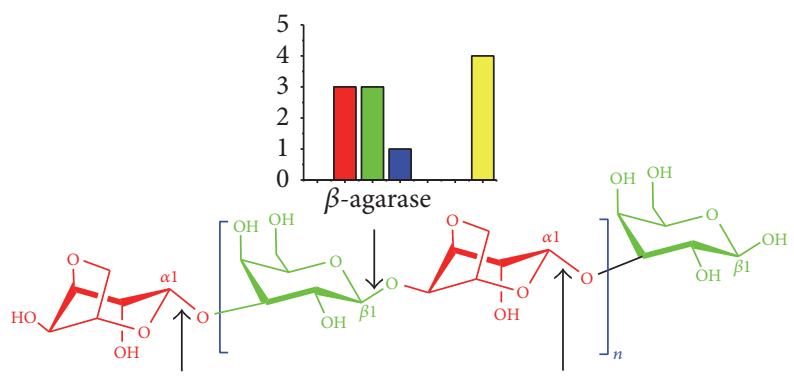

$\alpha$-1, 3-L-Neoagarooligosaccharide hydrolase
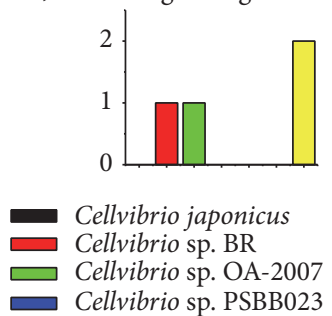

$$
\begin{aligned}
& \square \text { Cellvibrio mixtus } \\
& \square \text { Cellulomonas gilvus } \\
& \square \text { Cellvibrio sp. PR1 }
\end{aligned}
$$

(c) Agarose hydrolysis

Figure 3: Enzymes involving in cellulose (a), xylan (b), and agarose (c) hydrolysis and their encoding genes distributed in the genomes of Cellvibrio sp. PR1, Cellvibrio japonicus, and Cellvibrio sp. BR, Cellvibrio sp. OA-2007, Cellvibrio sp. PSBB023, Cellulomonas gilvus and Cellvibrio mixtus. 


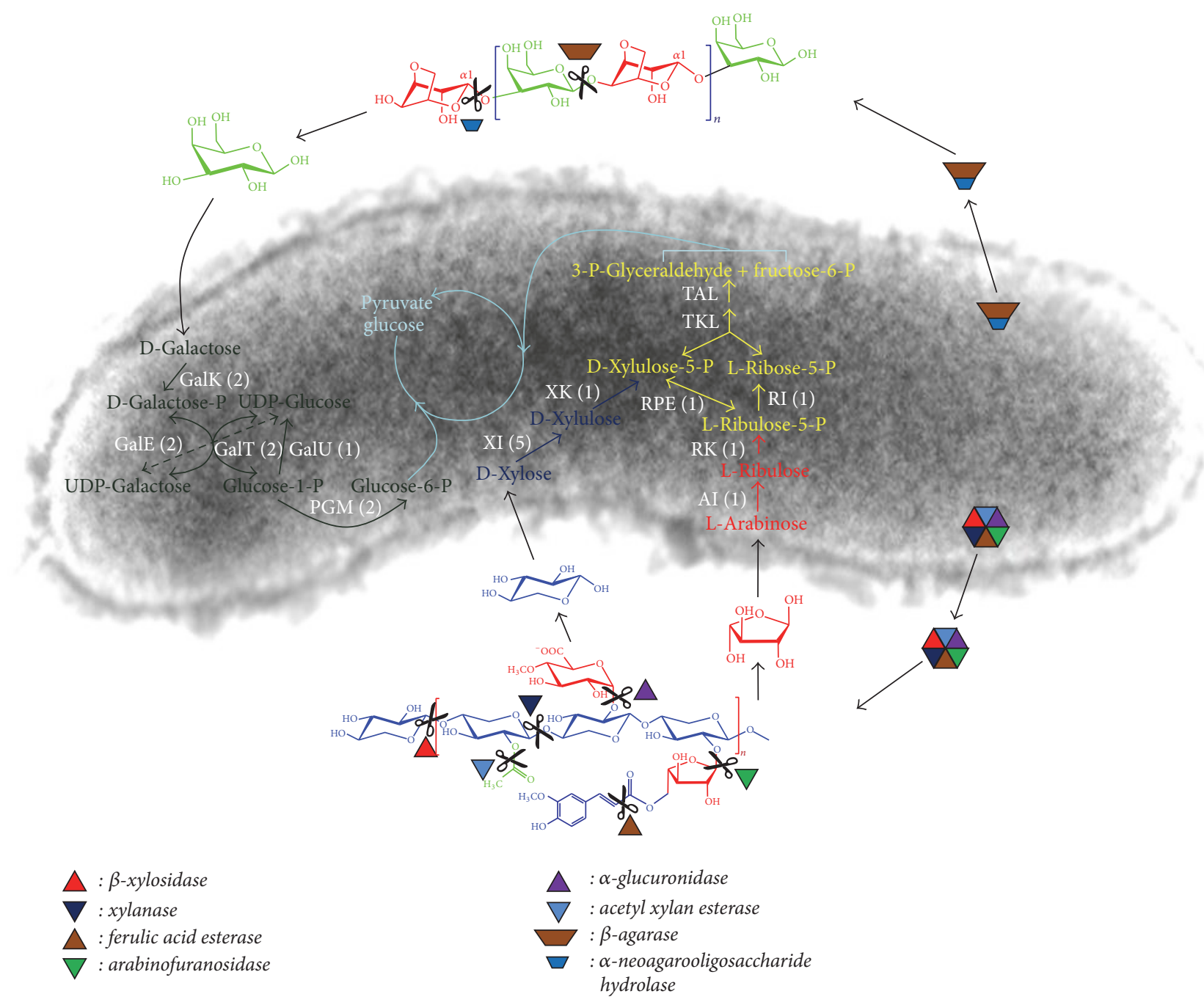

FIGURE 4: Xylan and agarose metabolic pathways in strain PR1 proposed on the genome-wide analysis. Yellow color marked pathway is the pentose phosphate pathway; the number in parenthesis is the gene copy found in the genome; GalK: galactokinase (EC 2.7.1.6); GalE: UDPglucose 4-epimerase (EC 5.1.3.2); GalT: UDP-glucose-hexose-1-phosphate uridylyltransferase (EC 2.7.7.12); GalU: UTP-glucose-1-phosphate uridylyltransferase (EC 2.7.7.9); PGM: phosphoglucomutase (EC 5.4.2.2); XI: xylose isomerase (EC 5.3.1.5); XK: xylulokinase (EC 2.7.1.17); AI: arabinose isomerase (EC 5.3.1.4); RK: ribulokinase (EC 2.7.1.16); RI: ribose 5-phosphate isomerase (EC 5.3.1.6); RPE: ribulose-phosphate 3-epimerase (EC 5.1.3.1); TKL: transketolase (EC 2.2.1.1); TAL: transaldolase (EC 2.2.1.2).

that were isolated from wastewater treatment plants [24] and sediments [25].

Strain PR1 has a higher xylanolytic activity than many other microorganisms [10]. Wu and $\mathrm{He}$ [10] concluded that the reason for the high xylanolytic activity of strain C. mixtus J3-8 was the abundance of GH11 xylanases; the xylanases located in GH11 are considerably more active than GH10 xylanase for its high substrate specificity, great stability and plasticity, and small protein sizes. In strain PR1, 2 GH10 and 2 GH11 xylanases were identified. However, the RNA-Seq results suggested the GH10 xylanase-encoding genes (FPKM: 1265 for PRGL001867 and 671 for PRGL003904) had higher expressions than GH11 xylanase-encoding genes (FPKM: 569 for PRGL000191 and 433 for PRGL003376) when xylan was used as the primary substrate [2]. The roles of GH10 and GH11 xylanases on xylan hydrolysis need to be further investigated by the kinetics of enzyme-catalyzed reactions and specific protein quantification.

CBMs are usually considered to promote hydrolysis efficiency by binding an enzyme to the substrate. In xylanase families GH10 and GH11, the catalytic modules are appended to a range of different CBMs that target crystalline cellulose (CBM 2 and CBM10) and xylan (CBM15 and CBM35) [9]. The C. japonicus Ueda107 was found to have CBM2-CBM10GH10, CBM2-CBM35-GH10, CBM15-GH10, and CBM60GH11 xylanases to release soluble polysaccharides and oligosaccharides [9]. Wu and $\mathrm{He}$ [10] detected 3 xylanasebinding CBMs (CBM2, CBM10, and CBM15) in strain $C$. mixtus J3-8. However, three CBM binding xylanases (CBM15GH10, CBM57-GH11, and CBM60-GH11) were identified for strain PR1, and neither CBM2 nor CBM10 was detected (Table S1). It seems that the CBM15 is a specific module that is only 
detected in Cellvibrio strains, such as C. japonicus, Cellvibrio sp. BR, and C. mixtus $[9,10,26]$.

In addition, six types of CBM (CBM5, CBM6, CBM12, CBM2-CBM6, CBM5-CBM12, and CBM6-CBM12) structures were detected from the binding domain of chitinases (GH18 and GH19) in strain PR1. GH18 chitinases are found in various organisms and are ordinarily composed of one catalytic domain and one or more domains that are involved in chitin binding, whereas GH19 chitinases are more likely to originate from plants and consisted of one or two domains [27]. Many chitinolytic bacteria produce only GH18 chitinases, and the production of both GH18 and GH19 was mostly reported in Streptomyces strains [27, 28]. The CBM5 shares similarities with some cysteine-rich chitin-binding domain $\left(\mathrm{ChBD}_{\mathrm{ChiC}}, \mathrm{ChBD}_{\mathrm{ChiAl}}\right.$, etc.) and were usually found in the binding domain of GH18 chitinases [27, 29]. However, very few chitin-binding CBM6 and CBM12 have been reported in bacteria. The comparative genome analysis suggested that there are three CBM5-GH18 and one CBM6-GH19 chitinases detected in C. japonicus Ueda107, and two CBM5-GH18 chitinases were detected in Cellvibrio sp. BR.

Strain PR1 was a syntrophic bacterium to cyanobacteria when enriching and isolating cyanobacterium under photoautotrophic condition. This strain was believed to be beneficial in cyanobacteria growth by the bacterial-algal interactions. Based on this hypothesis, we constructed a Cellvibrio-microalgae cocultivation model for the promotion of microalgae growth. The biomass production of Chlorella, Chlamydomonas, and Dunaliella was significantly enhanced by using this model; the comparative transcriptome analysis indicated that the xylan hydrolysates or xylose was catalyzed into some active substrates and responsible for the promotions [2]. The utilization of monosaccharides is important because the pentoses derived from hemicelluloses are difficult to ferment by microorganisms. Besides the organic carbon sources, vitamins or other growth factors of strain PR1 are possible substrates for enhancing microalgae growth. Strain PR1 has complete enzyme systems for vitamin $B_{1}$ (thiamine) and vitamin $\mathrm{B}_{7}$ (biotin) syntheses (Figures S1 and S2). The thiamine-synthesizing genes includes thiC (ThiC, phosphomethylpyrimidine synthase, EC4.1.99.17), thiD (ThiD, phosphomethylpyrimidine kinase, EC2.7.1.49), thiE (ThiE, thiamine-phosphate pyrophosphorylase, EC2.5.1.3), thiF (ThiF, adenylyltransferase, EC2.7.7.-), thiG (ThiG, thiazole synthase, EC2.8.1.10), thiI (Thil, thiamine biosynthesis ATP pyrophosphatase), thiL (ThiL, thiamine-monophosphate kinase, EC2.7.4.16), thiO (ThiO, glycine oxidase, EC1.4.3.19), thiS (ThiS, sulfur carrier protein), and $d x s$ (1-deoxy-Dxylulose-5-phosphate synthase, EC2.2.1.7). The biotinsynthesizing genes include bioA (adenosylmethionine-8amino-7-oxononanoate aminotransferase, EC2.6.1.62), bioB (biotin synthetase, EC2.8.1.6), bioC (methyltransferases), bioD (dethiobiotin synthetase, EC6.3.3.3), and bioF (8amino-7-oxononanoate synthase, EC2.3.1.47). It is known that over half of microalgal species are auxotrophic for cobalamin (vitamin $\mathrm{B}_{12}$ ), and $20 \%$ require thiamine, and $5 \%$ require biotin. The important role of vitamins in controlling algal growth is increasingly recognized $[30,31]$.
This study found that strain PR1 shows distinctive differences in phenotype and genome from known Cellvibrio species. The genomic analysis provides some insights into the functions of strain PR1 in polysaccharide hydrolysis and monosaccharide metabolism and possible syntrophic pattern with microalgae.

\section{Conflicts of Interest}

The authors declare that there are no conflicts of interests regarding the publication of this paper.

\section{Authors' Contributions}

Zhangzhang Xie and Weitie Lin contributed equally to this work.

\section{Acknowledgments}

This work was supported by the National Natural Science Foundation of China (no. 21276099; no. 41301318; no. 41473072), the Specialized Research Found for the Doctoral Program of Higher Education of China (no. 20120172120045), and the Fundamental Research Funds for the Central Universities (no. 2015ZM171).

\section{References}

[1] B. S. Harish, J. R. Mekala, and K. Babu Uppuluri, "Bioengineering strategies on catalysis for the effective production of renewable and sustainable energy," Renewable and Sustainable Energy Reviews, vol. 51, article no. 4568, pp. 533-547, 2015.

[2] Z. Xie, W. Lin, and J. Luo, "Promotion of microalgal growth by co-culturing with Cellvibrio pealriver using xylan as feedstock," Bioresource Technology, vol. 200, pp. 1050-1054, 2016.

[3] X. T. Fu and S. M. Kim, "Agarase: Review of major sources, categories, purification method, enzyme characteristics and applications," Marine Drugs, vol. 8, no. 1, pp. 200-218, 2010.

[4] S.-C. Wu, T.-N. Wen, and C.-L. Pan, "Algal-oligosaccharidelysates prepared by two bacterial agarases stepwise hydrolyzed and their anti-oxidative properties," Fisheries Science, vol. 71, no. 5, pp. 1149-1159, 2005.

[5] A. Grigorian, L. Araujo, N. N. Naidu, D. J. Place, B. Choudhury, and M. Demetriou, "N-acetylglucosamine inhibits T-helper 1 (Th1)/T-helper 17 (Th17) cell responses and treats experimental autoimmune encephalomyelitis," Journal of Biological Chemistry, vol. 286, no. 46, pp. 40133-40141, 2011.

[6] A. A. Klyosov, "Trends in biochemistry and enzymology of cellulose degradation," Biochemistry, vol. 29, no. 47, pp. 1057710585, 1990.

[7] J. A. Thomson, "Molecular biology of xylan degradation," FEMS Microbiology Letters, vol. 104, no. 1-2, pp. 65-82, 1993.

[8] Blackall et al., "Validation of the Publication of New Names and New Combinations Previously Effectively Published Outside the IJSB: List No. 22," International Journal of Systematic Bacteriology, vol. 36, no. 4, pp. 573-576, 1986.

[9] R. T. DeBoy, E. F. Mongodin, D. E. Fouts et al., "Insights into plant cell wall degradation from the genome sequence of the soil bacterium Cellvibrio japonicus," Journal of Bacteriology, vol. 190, no. 15, pp. 5455-5463, 2008. 
[10] Y.-R. Wu and J. He, "Characterization of a xylanase-producing Cellvibrio mixtus strain J3-8 and its genome analysis," Scientific Reports, vol. 5, Article ID 10521, 2015.

[11] G. I. Barrow and R. K. Feltham, Cowan and Steel's Manual for the identification of medical bacteria, Cambridge University Press, Cambridge, UK, 3rd edition, 1993.

[12] D. Han, H.-L. Cui, and Z.-R. Li, " Halopenitus salinus sp. nov., isolated from the brine of salted brown alga Laminaria," Antonie van Leeuwenhoek, International Journal of General and Molecular Microbiology, vol. 106, no. 4, pp. 743-749, 2014.

[13] J. J. McDade and R. H. Weaver, "Rapid methods for the detection of gelatin hydrolysis," Journal of Bacteriology, vol. 77, no. 1, pp. 60-64, 1959.

[14] M. Mesbah, U. Premachandran, and W. B. Whitman, "Precise measurement of the $\mathrm{g}+\mathrm{c}$ content of deoxyribonucleic acid by high-performance liquid chromatography," International Journal of Systematic Bacteriology, vol. 39, no. 2, pp. 159-167, 1989.

[15] J. R. M. Delamuta, R. A. Ribeiro, E. Ormeño-Orrillo, I. S. Melo, E. Martínez-Romero, and M. Hungria, "Polyphasic evidence supporting the reclassification of Bradyrhizobium japonicum group Ia strains as bradyrhizobium diazoefficiens sp. nov," International Journal of Systematic and Evolutionary Microbiology, vol. 63, no. 9, pp. 3342-3351, 2013.

[16] J. D. Thompson, T. J. Gibson, F. Plewniak, F. Jeanmougin, and D. G. Higgins, "The CLUSTAL X windows interface: flexible strategies for multiple sequence alignment aided by quality analysis tools," Nucleic Acids Research, vol. 25, no. 24, pp. 48764882, 1997.

[17] K. Tamura, D. Peterson, N. Peterson, G. Stecher, M. Nei, and S. Kumar, "MEGA5: molecular evolutionary genetics analysis using maximum likelihood, evolutionary distance, and maximum parsimony methods," Molecular Biology and Evolution, vol. 28, no. 10, pp. 2731-2739, 2011.

[18] Z. Xie, W. Lin, and J. Luo, "Genome sequence of Cellvibrio pealriver PR1, a xylanolytic and agarolytic bacterium isolated from freshwater," Journal of Biotechnology, vol. 214, pp. 57-58, 2015.

[19] B. I. Cantarel, P. M. Coutinho, C. Rancurel, T. Bernard, V. Lombard, and B. Henrissat, "The Carbohydrate-Active EnZymes database (CAZy): an expert resource for glycogenomics," Nucleic Acids Research, vol. 37, no. 1, pp. D233-D238, 2009.

[20] Y. Yin, X. Mao, J. Yang, X. Chen, F. Mao, and Y. Xu, “DbCAN: A web resource for automated carbohydrate-active enzyme annotation," Nucleic Acids Research, vol. 40, no. 1, pp. W445W451, 2012

[21] G. L. Miller, "Use of dinitrosalicylic acid reagent for determination of reducing sugar," Analytical Chemistry, vol. 31, no. 3, pp. 426-428, 1959.

[22] D. R. Humphry, G. W. Black, and S. P. Cummings, "Reclassification of 'Pseudomonas fluorescens subsp. cellulosa' NCIMB 10462 (Ueda et al. 1952) as Cellvibrio japonicus sp. nov. and revival of Cellvibrio vulgaris sp. nov., nom. rev. and Cellvibrio fulvus sp. nov., nom. rev," International Journal of Systematic and Evolutionary Microbiology, vol. 53, no. 2, pp. 393-400, 2003.

[23] J. Mergaert, D. Lednická, J. Goris, M. C. Cnockaert, P. De Vos, and J. Swings, "Taxonomic study of Cellvibrio strains and descriptin of Cellvibrio ostraviensis sp. nov., Cellvibrio fibrivorans sp. nov. and Cellvibrio gandavensis sp. nov," International Journal of Systematic and Evolutionary Microbiology, vol. 53, no. 2, pp. 465-471, 2003.
[24] G. Paës, J.-G. Berrin, and J. Beaugrand, "GH11 xylanases: structure/function/properties relationships and applications," Biotechnology Advances, vol. 30, no. 3, pp. 564-592, 2012.

[25] Y. J. Rhee, C. R. Han, W. C. Kim, D. Y. Jun, I. K. Rhee, and Y. H. Kim, "Isolation of a novel freshwater agarolytic cellvibrio sp. KYYJ-3 and characterization of its extracellular $\beta$-agarase," Journal of Microbiology and Biotechnology, vol. 20, no. 10, pp. 1378-1385, 2010.

[26] S. J. Millward-Sadler, K. Davidson, G. P. Hazlewood, G. W. Black, H. J. Gilbert, and J. H. Clarke, "Novel cellulose-binding domains, NodB homologues and conserved modular architecture in xylanases from the aerobic soil bacteria Pseudomonas fluorescens subsp. cellulosa and Cellvibrio mixtus," Biochemical Journal, vol. 312, no. 1, pp. 39-48, 1995.

[27] Y. Kezuka, M. Ohishi, Y. Itoh et al., "Structural Studies of a Two-domain Chitinase from Streptomyces griseus HUT6037," Journal of Molecular Biology, vol. 358, no. 2, pp. 472-484, 2006.

[28] T. Watanabe, R. Kanai, T. Kawase et al., "Family 19 chitinases of Streptomyces species: Characterization and distribution," Microbiology, vol. 145, no. 12, pp. 3353-3363, 1999.

[29] M. Hardt and R. A. Laine, "Mutation of active site residues in the chitin-binding domain $\mathrm{ChBD}_{\mathrm{ChiAl}}$ from chitinase $\mathrm{A} 1$ of Bacillus circulans alters substrate specificity: use of a green fluorescent protein binding assay," Archives of Biochemistry and Biophysics, vol. 426, no. 2, pp. 286-297, 2004.

[30] M. T. Croft, M. J. Warren, and A. G. Smith, "Algae need their vitamins," Eukaryotic Cell, vol. 5, no. 8, pp. 1175-1183, 2006.

[31] M. A. A. Grant, E. Kazamia, P. Cicuta, and A. G. Smith, "Direct exchange of vitamin $B_{12}$ is demonstrated by modelling the growth dynamics of algal-bacterial cocultures," ISME Journal, vol. 8, no. 7, pp. 1418-1427, 2014. 

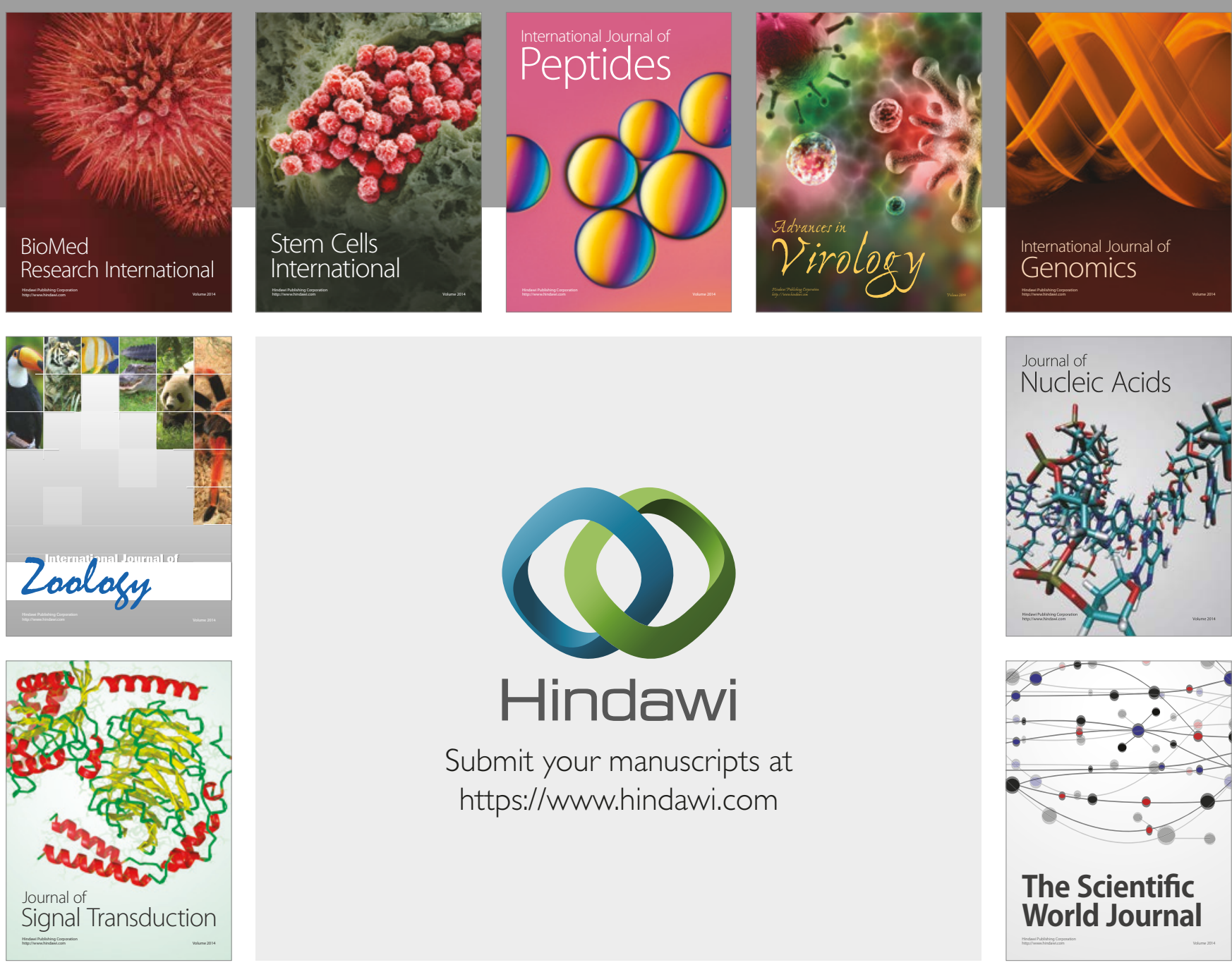

Submit your manuscripts at

https://www.hindawi.com
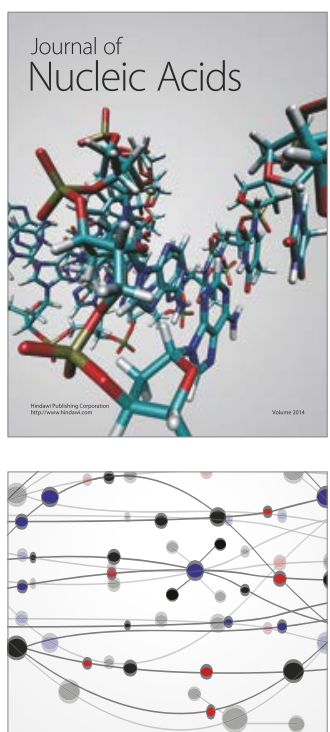

The Scientific World Journal

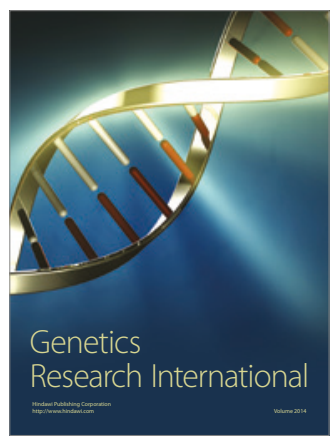

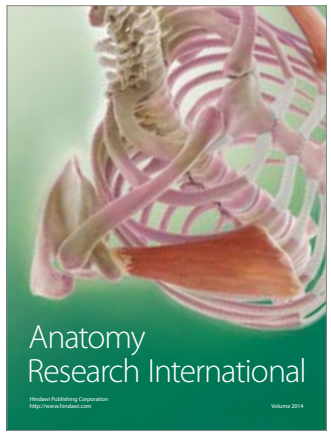

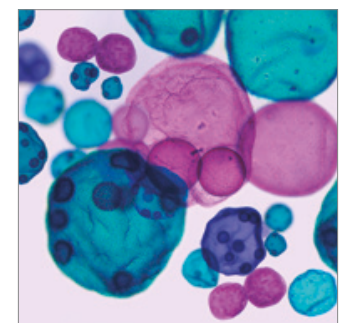

International Journal of Microbiology
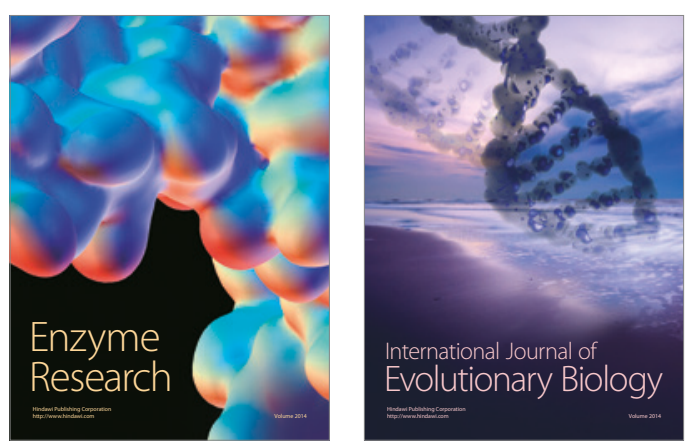
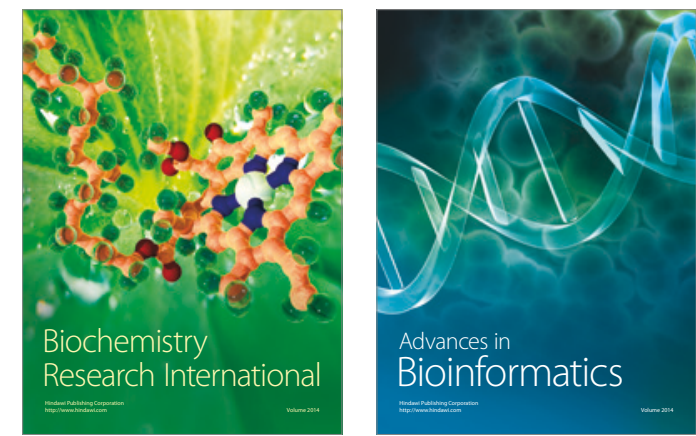

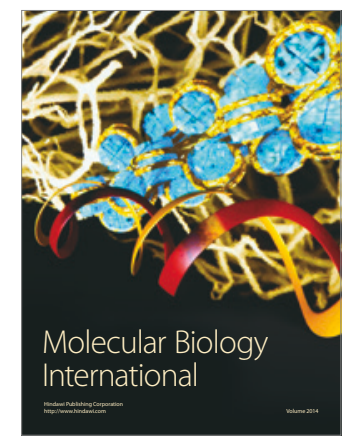

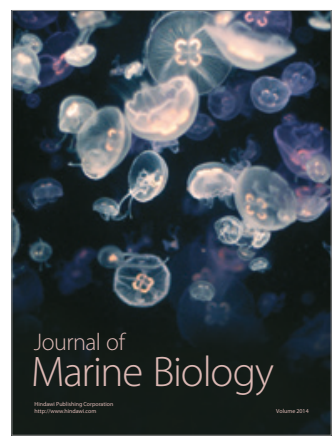

